GLOBAL JOURNAL OF EDUCATIONAL RESEARCH VOL 9, NO. 1\&2 2010: 1-5 COPYRIGHT@ BACHUDO SCIENCE CO. LTD PRINTED IN NIGERIA. ISSN 1596-6224 www.globaljournalseries.com; Info@globaljournalseries.com

\title{
EFFECT OF GENERAL AND SPECIFIC BEHAVIOURAL OBJECTIVES ON STUDENTS' ACHIEVEMENT PRIOR TO INSTRUCTION IN SOCIAL STUDIES.
}

S. D. EDINYANG AND I. E. UBI

(Received 10, November 2009; Revision Accepted 11, March 2009)

\begin{abstract}
The study of general and specific behaviourial objectives on students' achievement prior to instruction in social studies was carried out in order to determine its relative effectiveness in improving the performance of students in both internal and external examinations in Akwa lbom State schools of Nigeria. Relevant literature was reviewed. A total of 270 junior secondary two students were used for the study. The instrument consisted of thirty multiple choice objective questions and a questionnaire. The research design adopted for the study was pretest-post test control group experimental design. Three Social Studies topics were taught within an eight week duration of the field work. One hypothesis was postulated for the study and tested at 0.05 level of significance using analysis of covariance (ANOVA). The results of the data analysis indicated that students presented with specific behavioural objectives prior to instruction in social studies had a significantly higher academic achievement than those presented with general objectives, who in turn had a significantly higher academic achievement than those presented with no objective. Based on this finding some recommendations were made.

\section{INTRODUCTION}

The teaching and learning of social studies could be either very simple and easy going or very complex and difficult depending on the ability of the teacher to make effective use of either general or specific behavioural objectives in interacting with the learners. Before this period, most teachers in the process of preparing lesson notes simply write down a brief explanation of the aim of social studies as expressed in terms of content to be learned or skill to be acquired. Such aims were simply to guide teachers in their teaching and learning session without availing the learners of these objectives to enable them focus on the lesson in order to aid their achievement of the lesson. Now, educational practice view curriculum as a cyclical process which involves the selection of objectives to be achieved in social studies. Thus there is need for a final provision of feedback that will inform students of their success and failure and provide

them a springboard for further endeavour (Amadi 1990). In an attempt to optimize effective teaching and learning, a shift is always being made from the general educational aims to specific objectives which are achieved at the end of a social studies course or series of lessons. These are usually expressed in the form of what students are expected to do as a result of instruction.

However, it is very pertinent to observe that while some individuals such as Popham (1969) and Bigelaw (1992) are in strong support for the use of specific behaviourial objectives for planning instruction, some writers such as Mager (1962) and Macdonald (1973) are strongly against the use of either general or specific behavioural objectives in the teaching process.

According to Mkpa (1986:31-35) objective has a strong influence in students' achievement because

i. objectives assist learners in the selection of appropriate subject matter, materials and methods.
\end{abstract}

S. D. Edinyang, Curriculum and Teaching Department, Faculty of Education University of Calabar, Nigeria.

I. E. Ubi, Curriculum and Teaching Department, Faculty of Education University of Calabar, Nigeria. 
ii. Well stated objectives tell students the points that are considered most important and on which to focus attention in the syllabus.

iii. Learners are guided in their private studies by statements of objectives.

iv. Statements of behavioural objectives provide the much needed feedback both to the teacher and the students.

v. Objectives clarify and give meaning to what is learned.

vi. Objectives are used in planning instruments.

Edinyang (2008) also adds that Objectives

vii. Provide goals towards which the curriculum is aimed.

viii. Make it possible to evaluate the outcomes of the curriculum.

ix. Re-teach an unsuccessful lesson.

$x$. Abandon the lesson on the basis of new data.

xi. Extend the learning from his lesson.

xii. Move to the next appropriate learning.

This work is not to take side with those against the use of either general or specific behavioural objectives for planning instrument, neither is it a blind support for their usage. The study rather seeks to empirically determine whether prior knowledge of general and specific behavioural objectives, if well used by the teachers and students can:

i. Have any effect on students' academic achievement and retention in social studies.

ii. Contribute towards putting a stop to students' poor performance in the subject at both internal and external examinations and;

iii. Heighten the standard of educational attainment in social studies in Akwa Ibom State and Nigeria at large.

\section{Statement of problem}

If teachers were to, prior to instruction, intimate students or expose them to either general objectives or specific behavioural objectives the pertinent question world have been, to what extent will students exposed to general objectives or specific behavioural objectives perform differently in achievement tasks in social studies from those who were not?

\section{Purpose of the study}

The purpose of the study is to determine if there is any difference in academic achievement of students who had prior knowledge of general and specific objective and those who did not.

\section{Research Question}

To what extent do students with prior knowledge of stated general and specific objectives perform higher in achievement test than those without?

\section{Statement of hypothesis}

There is no significant difference in the academic achievement of students presented with statement of general and specific behavioural objectives prior to instruction in social studies and those not presented.

\section{METHODOLOGY}

The design used for this study is pretest, posttest control group experimental design. The design is adopted because it allows the independent variables which are general and behavioural objectives to be manipulated in order to determine their effect on the dependent variable which is achievement in social studies.

The study population comprised 1800 JSS II students from 23 public post primary schools in Nsit Atai and Nsit Ubium local Government areas of the state. The study had a sample of 270 respondents, the simple random sampling technique was used for the selection.

The instruments used in the collection of data for this study were a test and a questionnaire. The test was a pretest and a posttest which were administered to both the control and experimental groups. The tests were made of thirty objective questions each.

In order to ascertain that this instrument could reliably serve its objective, a trial testing instrument was conducted. The split half reliability method was used in computing the reliability co-efficient. The correlation co-efficient reliability was $r x y=0.44$ and the Spearman brown prophecy value was $t=0.61$. This result suggest 
that the instrument had the necessary requisite needed to effectively and adequate generate the data needed for the study.

\section{RESULT}

There are three groups of students that are involved and each student was given a pretest and posttest to determine their academic achievement.

The data collected were analyzed using one factor analysis of covariance (ANCOVA) with the pretest scores as covariate. The results are shown below:

\section{Hypothesis I:}

There is no significant difference in the academic achievement of students presented with statement of general and specific objective prior to instruction in social studies and those not presented.

Table 1

Adjusted mean, Mean, Standard deviation and ANCOVA of academic achievement of students taught Social Studies by presenting them with general, specific and no behavioural objectives prior to instruction with pretest as covariate.

\begin{tabular}{|c|c|c|c|c|c|}
\hline Treatment Group & $\overline{\bar{X}(\text { adjusted })}$ & $\overline{\bar{x}}$ & $\overline{\mathrm{SD}}$ & & $\bar{N}$ \\
\hline $\begin{array}{l}\text { General } \\
\text { objective }\end{array}$ & 56.298 & 56.122 & 12.492 & & 90 \\
\hline $\begin{array}{l}\text { Specific } \\
\text { objective }\end{array}$ & 72.540 & 72.711 & 11.898 & & 90 \\
\hline No objective & 49.351 & 49.356 & 11.954 & & 90 \\
\hline $\begin{array}{l}\text { Source of } \\
\text { variation }\end{array}$ & Sum of squares & df & Mean square & $\mathbf{F}$ & \\
\hline pretest & 14068.708 & 1 & 1468.70 & 149 & $.535^{*}$ \\
\hline Treatment & 25489.069 & 2 & 12744.585 & 135 & $.161^{*}$ \\
\hline Error & 25026.059 & 266 & 94.083 & & \\
\hline Total & 64583.936 & 269 & & & \\
\hline
\end{tabular}

${ }^{*} \mathrm{P}<.05 \mathrm{~F} .05(.266)=3.89 \mathrm{~F} .05(2,266)=3.04$.

As shown in Table 1, the mean achievement for students presented with specific objectives prior to instruction $(x=72.711, S=11.898)$ is greater than that of those presented with general objectives $(x=56.122, \mathrm{~S}-12.492)$ which is in turn greater than that of students not presented with objectives $(x=49.356, S=11.954)$. The same trend holds for the adjusted means. This observed difference is statistically significant, since the calculated $f$ value for treatment which is 42.514 is far greater than the critical F-value of
3.04 at .05 significance level and (2.266) degrees of freedom. This means that when the posttest achievement scores of the students are adjusted for the linear effects of the pretest scores, there is significant difference in the academic achievement of the three treatment groups.

In order to determine the point(s) of differences, a post hoc pairwise comparison of the adjusted means was conducted using Fischer's LSD techniques. The results are shown in Table 2. 
Table 2

Post hoc comparison of the difference in adjusted means of the three treatment groups using Fishers

\begin{tabular}{|l|l|l|l|l|}
\hline & Treatment Groups & 1 & 2 & 3 \\
\hline 1 & General objective & $56.298^{\mathrm{a}}$ & $16.242^{\mathrm{b}}$ & $6.946^{*}$ \\
\hline 2 & Specific objective & $.000^{\mathrm{c}}$ & 72.540 & $23.189^{*}$ \\
\hline 3 & No objective & .000 & .000 & 49.351 \\
\hline
\end{tabular}

N.B a - Adjusted means are along the principal diagonal

b - $\quad$ Differences between adjusted means are above the principle diagonal

c - Computer generated significance levels of the differences between adjusted means are below the principal diagonal ${ }^{*} \mathrm{p}<.05$

The result in Table 2 indicated that students presented with specific behavioural objectives prior to instruction in Social Studies have a significantly greater adjusted mean score than those presented with general objectives and those not presented with objectives. Similarly, students presented with general objectives have a significantly greater mean score than those not presented with objectives.

\section{Finding and Discussion}

The high performance of the experimental groups (general and specific behavioural objectives) over the control group (the non objectives group) and the high retention ability of students presented with general and specific behavioural objective prior to instruction over the students not presented with statement of objectives could be rightly attributed to the effect of instructional objectives. Since the experimental groups discussed and wrote down the objectives prior to instruction and the achievement and retention tests were largely based on the objective, the experimental groups (general and specific behavioural objectives) must have had an advantage of utilizing the objectives for their review or private studies preparatory to the examination. In doing this, they must have selectively focused attention on those vital areas of learning which the objectives pointed to.

In the other words, it can be effectively argued that the general and specific behavioural objectives groups respectively had already known what is expected of them in examinations and tests (as far as the topics they were taught was concerned) and they therefore prepared their answers and reproduced them adequately. It can be argued too that general and specific objectives in this case acted as "expose" to the students because they have already been availed of what is expected of them at the end of lessons and indeed tests and examinations as seen in Table 1 where the mean achievement for students presented with specific objectives prior

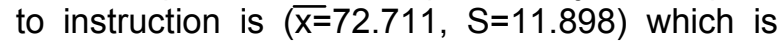
greater than that of those presented with general objectives $(\bar{X}=56.122, S=11.954)$. The same trend holds for the adjusted means. This observed difference in the means performance of the three groups of students is statistically significant, since the calculated F-value for treatment which is 42.514 is far greater than the critical F-value of 3.04 at .05 significance level and $(2,266)$ degrees of freedom.

The control group, which is the group with non-objectives, were not exposed to either general or specific behavioural objectives prior to instruction. Thus the group in preparing for the test did not have any focus as did the experimental groups. Moreso, there is a significant difference in the retention ability of students exposed to general, specific behavioural objectives and those not presented.

This is in agreement with the views expressed by Raghubir (1979), that performance improves when students are provided with learning outcomes and how to go about them. He observed that students receiving instruction with prior knowledge of learning outcomes achieve significantly higher on immediate and delayed post-test measures of performance. Ragbubir (1979) observed that:

The effectiveness of providing students with precisely stated learning outcomes and the ability to use them (i) enhanced students performance on achievement test (ii) helped students retain the material they had learned longer than the ones who studied the material without learning outcomes did and (iii) resulted in a greater understanding of 
cognitive behaviours higher than the knowledge level (p. 303).

The results of this study agrees with Cohem's and Hill's review (1997), of a research that concerned with the effect of learning of inserting questions into given texts. He argued that behavioural objectives and inserted questions are very similar in that both show students what they should be able to do as a result of the learning process. He further argued that if behavioural objectives were used in similar situation as inserted questions that the following expectations are valid. Objectives might be expected to function as orienting or as reinforcement stimuli according to whether they are placed immediately before or after the related instructional material. He concluded that both pre and post-objectives enhance relevant learning in that they function as orienting stimuli.

However, it could be said that prior knowledge of a learning outcome has positive correlation with academic achievement. The superior performance of the experimental groups in the achievement test seemed to be carried over to the retention test as a result of two essential factors the influence of instructional objectives and the fact that the achievement test were similar except in the serial order of item arrangement. The findings of these studies in which the objectives instruction groups (general and specific behavioural objectives) significantly out scored traditional instruction group (the non objectives group) in retention supports what Robbins (1989) had earlier reported

From the data in Table 1 - 2 of this study, it could be seen that there is a significant difference in achievement between the general and specific behavioural objectives group. This is because the more specific the objective is, the more target oriented it is as compared to the general objectives which are vague and ambiguous and non target, non focus. Moreso, because specific behaviour objective are target and focus oriented, students can predict what is expected of them in test and examination as compared to the general objectives group where students would have to work "aimlessly" to know what is expected of them in examination.
RECOMMENDATION AND CONCLUSION

From the result of the data analysis the study recommends and concludes that effort be made by government to organize regular refresher courses, professional workshops and seminars for practicing teachers to keep them in line with current strategies and techniques for effective teaching/learning engagement in the use of specific objectives.

\section{REFERENCES}

Amadi, L. E., 1990. Principles of curriculum development $\left(2^{\text {nd }}\right.$ edition) Uyo: Legacy Publishers.

Bigelaw, M. L., 1992. The effects of information processing strategies and cognitive style in achievement of selected educational objectives. Pennsylvania State University.

Cohen, D. K. \& Hill, H., 1997. Instructional policy and classroom performance; The mathematic reform in California. Paper presented at the annual meeting of the American Educational Research association: Chicago, $\mathrm{K}$.

Edinyang, S. D., 3008. The relative effectiveness of inquiry and expository methods of teaching social studies on the academic performance of students in Akwa Ibom State schools. Journal of Higher Education in Africa 6: p 144-152.

Macdonald, R. M., 1973. Behavioural objectives: A critical review, Instructional science. 2.1-52.

Mager, R. F., 1962. Preparing Instructional Objective. Belmout: Pitman Learning.

Mkpa, A. M., 1986. Curriculum design and instructional evaluation. Ibadan: Evans Brothers (Nigeria) Ltd. 
Popham, W. J., 1969. Objectives and instruction in W. J. Popham, E. W. Eisher, H. J. Succivan and L. C. Tyler (Eds) Instructional Objectives._45-60, Chicago: Rand Monarchy.

Raghubir, K. P., 1979. The effect of prior knowledge of learning outcome on students achievement and retention in science instruction. Journal of Research in Science Teaching, 16 (4) p. 301-304.

Robin, A. L., 1989 Behavioural Instruction in the College Classroom. Review of Educational Research, 45(2), p. 215-317. 